\title{
Metal/ceramic interface structures and segregation behavior in aluminum-based composites
}

Xinming Zhang ${ }^{1}$, Tao Hu ${ }^{1}$, Jorgen F. Rufner ${ }^{1}$, Thomas LaGrange ${ }^{2 *}$, Geoffrey H. Campbell ${ }^{2}$,

\author{
Enrique J. Lavernia ${ }^{1}$, Julie M. Schoenung ${ }^{1}$, Klaus van Benthem ${ }^{1}$ \\ ${ }^{1}$ Department of Chemical Engineering and Materials Science, University of California, Davis, CA \\ 95616 \\ ${ }^{2}$ Physical and Life Sciences Directory, Lawrence Livermore National Laboratory, 7000 East Ave, \\ Livermore, CA 94550
}

\begin{abstract}
Trimodal Al alloy (AA) matrix composites consisting of ultrafine-grained (UFG) and coarsegrained (CG) $\mathrm{Al}$ phases and micron-sized $\mathrm{B}_{4} \mathrm{C}$ ceramic reinforcement particles exhibit combinations of strength and ductility that render them useful for potential applications in the aerospace, defense and automotive industries. Tailoring of microstructures with specific mechanical properties requires a detailed understanding of interfacial structures to enable strong interface bonding between ceramic reinforcement and metal matrix, and thereby allow for effective load transfer. Trimodal AA metal matrix composites typically show three characteristics that are noteworthy: nanocrystalline grains in the vicinity of the $\mathrm{B}_{4} \mathrm{C}$ reinforcement particles; $\mathrm{Mg}$ segregation at $A A / B_{4} C$ interfaces; and the presence of amorphous interfacial layers separating nanocrystalline grains from $\mathrm{B}_{4} \mathrm{C}$ particles. Interestingly, however, fundamental information related to the mechanisms responsible for these characteristics as well as information on local compositions and phases are absent in the current literature. In this study, we use high-resolution transmission electron microscopy, energy-dispersive X-ray
\end{abstract}

\footnotetext{
* Now at: Ecole Polytechnique Federale Lausanne, Switzerland
} 
spectroscopy, electron energy-loss spectroscopy, and precession assisted electron diffraction to gain fundamental insight into the mechanisms that affect the characteristics of $A A / B_{4} C$ interfaces. Specifically, we determined interfacial structures, local composition and spatial distribution of the interfacial constituents. Near atomic resolution characterization revealed amorphous multilayers and a nanocrystalline region between $\mathrm{Al}$ phase and $\mathrm{B}_{4} \mathrm{C}$ reinforcement particles. The amorphous multilayers consist of nonstoichiometric $\mathrm{Al}_{x} \mathrm{O}_{y}$, while the nanocrystalline region is comprised of $\mathrm{MgO}$ nanograins. The experimental results are discussed in terms of the possible underlying mechanisms at $A A / B_{4} C$ interfaces.

\section{Introduction}

Nanostructured $(<100 \mathrm{~nm})$ and ultrafine-grained $(100-500 \mathrm{~nm})$ materials are noteworthy because they provide an opportunity to study the influence of microstructural dimensions on mechanical behavior. Remarkable enhancements to mechanical strength and physical performance have been documented for such materials [1-4]. One strategy to produce nanostructured or UFG materials involves severe plastic deformation (SPD) using, for instance, equal channel angular pressing, high pressure torsion [5], surface mechanical attrition treatment [6], and ball milling $[2,7]$. A derivative of ball milling that has been broadly used to prepare nanocrystalline microstructures is cryogenic ball milling (cryomilling), which takes advantage of cryogenic temperatures to suppress dynamic recrystallization by dissipating heat generated during the milling process [2]. Regardless of the synthesis technique, room temperature ductility and strain hardening of nanocrystalline materials are generally degraded by the limited dislocation activity that occurs at these grain sizes [8-11]. A number of 
approaches, such as the introduction of coarse grains, precipitate particles and promoting twin formation, have been successfully used to enhance the ductility of nanocrystalline materials[12]. Another approach involves the development of trimodal metal matrix composites, which consist of a coarse grained (CG) structure (larger than $1 \mu \mathrm{m}$ grain size), an ultrafine-grained (UFG) structure, and micron-sized $\mathrm{B}_{4} \mathrm{C}$ reinforcement particles [13-16]. The CG structure is employed to provide ductility, while the UFG structure facilitates grain boundary strengthening due to, e.g., the Hall-Petch relationship. The $\mathrm{B}_{4} \mathrm{C}$ particles pin the movement of dislocations to further resist plastic deformation, lower the material's density and increase the elastic modulus of the metal matrix composite.

Inspection of the published literature shows that the mechanical behavior of trimodal composites has been studied for the past decade $[13-15,17,18]$. A widely used matrix is Al-Mg partly due to the excellent balance of strength, weldability and corrosion resistance of this family of alloys [19]. The original trimodal composite [14], consisting of $10 \mathrm{wt} . \%$ micron-sized $\mathrm{B}_{4} \mathrm{C}, 40$ wt.\% UFG $5083 \mathrm{AA}$ and 50 wt.\% CG 5083 AA, was manufactured through cryomilling, blending, cold isostatic pressing and extrusion. This composite exhibited ultra-high compression yield strength of $1065 \mathrm{MPa}$. Early trimodal composites established themselves as attractive alternatives to conventional armor steel due to their excellent dynamic deformation behavior, with strain-to-failure of $14 \%$ at strain rates on the order of $10^{3} \mathrm{~s}^{-1}$ and strength values as high as $1000 \mathrm{MPa}[13,20]$. However, widespread application of the early trimodal composites was restrained by their limited strain-to-failure $(0.8 \%)$ when tested under quasi-static compression, and failure prior to yielding when tested under tensile loading. 
Modifications of the trimodal composite with a higher content of the CG phase led to tensile yielding but with limited elongation (1-2\%) [15]. More recently, Zhang et al. [21] showed that nanometric $\mathrm{B}_{4} \mathrm{C}$ reinforcement suppressed stress/strain localization and thereby improved plasticity. In this particular study a trimodal composite consisting of $3.5 \mathrm{wt} \%$ nanosized $\mathrm{B}_{4} \mathrm{C}, 30$ wt.\% CG $5083 \mathrm{AA}$ and the balance UFG 5083 AA was reported to exhibit a strength above $630 \mathrm{MPa}$ with a tensile strain of $3 \%$ [21].

A critical requirement for the application of trimodal composites is the creation of a strong interfacial bond between ceramic reinforcement and metal matrix to allow for effective load transfer. To that effect, the interfacial structures that form between $\mathrm{Al}$ and $\mathrm{B}_{4} \mathrm{C}$ reinforcements in 5083 AA trimodal composite have been studied using high resolution transmission electron microscopy (HRTEM) $[8,17,22]$. Li et al. $[17,22]$ reported the presence of amorphous layers, with a typical thickness between 5-8 $\mathrm{nm}$, separating $\mathrm{B}_{4} \mathrm{C}$ particles and the UFG Al phase. The authors suggested that the interfacial layers likely originated from the native surface oxide of 5083 AA during processing [17], but detailed studies were not conducted to ascertain the origin of these layers. Hence, the possibilities that the interface layers originated from either amorphization of crystalline $\mathrm{B}_{4} \mathrm{C}$ [23] under shock load or from amorphous boron oxide [24] due to surface oxidation were not considered.

The formation of one to three layers of nanocrystalline grains with diameters of approximately $30-50 \mathrm{~nm}$ at the $\mathrm{Al} / \mathrm{B}_{4} \mathrm{C}$ interface has also been reported previously $[8,22]$. Segregation of $\mathrm{Mg}$ to $\mathrm{Al} / \mathrm{B}_{4} \mathrm{C}$ interfaces was demonstrated using electron energy loss spectroscopy (EELS) and energy-dispersive X-ray spectroscopy (EDXS) [17,25]. Vogt et al. 
suggested that nucleation of micro-cracks approximately $100 \mathrm{~nm}$ away from the $A A / B_{4} C$ interfaces may have led to failure during compression testing [13]. However, studies of interfacial phenomena focused on only small length fractions of grain boundaries and did not provide a global understanding of the characteristics and possible influence of interfacial composition and structure. For example, no energy-loss near-edge fine structure (ELNES) studies have been performed to provide bonding information for the elements segregated to the interface. Hence, information on the relationship between different interface morphologies (e.g., amorphous layers, nanocrystalline grains, etc.) and their chemical composition profiles remains absent in the literature.

In view of the above discussion, we determine microstructure information from HRTEM, EDXS, EELS, and precession assisted electron diffraction. The experimental results are used to ascertain a fundamental insight into the mechanisms that affect the characteristics of $\mathrm{Al} / \mathrm{B}_{4} \mathrm{C}$ interfaces.

\section{Experimental details}

\subsection{Materials synthesis}

The feedstock powders used to produce trimodal Al matrix composites were gas-atomized 5083 AA (4.5 wt.\% Mg, 0.57 wt.\% Mn, 0.25 wt.\% Fe balanced with Al) provided by Valimet, Inc. (Stockton, CA) and $\mathrm{B}_{4} \mathrm{C}$ powder (Tetrabor $\mathrm{C}$, F1200) from ESK Ceramics (Saline, MI). The asreceived 5083 AA powder had an average particle size below $45 \mu \mathrm{m}$. The particle size for the asreceived $B_{4} C$ powder ranged from 1-7 $\mu$ m [26]. The composite powder was fabricated via cryomilling [2] of 14 wt.\% $\mathrm{B}_{4} \mathrm{C}$ and 76 wt.\% UFG 5083 AA for 24 hours using stainless steel balls 
as grinding media. Chemical analysis of the cryomilled powder was completed by Luvak, Inc. (Boylston, MA) and Shiva Technologies (Syracuse, NY). Non-metallic elements were measured using combustion infrared detection and inert gas fusion, while metallic elements were measured using direct current plasma emission spectroscopy. The chemical composition analysis of the as-cryomilled powder before mixing with CG 5083 AA is shown in Table 1 [26]. After cryomilling the powder was mixed with CG 5083 AA.

The mixed powder consisting of three different components was compacted to approximately $50 \%$ relative density inside a nitrogen glove box and subsequently degassed in a furnace to remove hydrogen and oxygen introduced by the surfactant (stearic acid) used during milling. Degassing was performed at $4 \times 10^{-5}$ Torr while the sample was heated over 4 hours up to $400^{\circ} \mathrm{C}$ with a holding time of 8 hours. Degassing was considered completed when the pressure reached $2 \times 10^{-6}$ Torr. Degassed powders were subsequently consolidated by hot isostatic pressing (HIP) at $400 \pm 4^{\circ} \mathrm{C}$ and $101.3 \pm 1.7 \mathrm{MPa}$ for 4 hours. Extrusion was used for secondary consolidation at a rate of $48.8 \mathrm{~m} / \mathrm{min}$. To aid with the deformation during extrusion, the billets were pre-heated in a furnace at $525^{\circ} \mathrm{C}$ for 30 minutes and then extruded at a ratio of 6.5:1. The final product is designed to consist of 10 wt.\% $B_{4} C, 30$ wt.\% CG $5083 \mathrm{AA}$, and the balance of UFG 5083 AA [25]. The grain sizes of these micro constituents after consolidation were determined through TEM to be $400-600 \mathrm{~nm}, 600-2600 \mathrm{~nm}$, and $174 \pm 100 \mathrm{~nm}$, respectively. More detailed information about the synthesis procedure is published elsewhere $[14,18,25,26]$. 
Table 1 Chemical analysis of cryomilled powder after milling for $24 \mathrm{hrs}$.

\begin{tabular}{|c|c|c|c|c|}
\hline O (wt. \%) & $\mathrm{H}$ (ppm) & $\mathrm{N}$ (wt. \%) & Fe (wt. \%) & $\mathrm{Mn}$ (wt. \%) \\
\hline 12.64 & 1263 & 3.10 & 0.47 & 0.57 \\
\hline
\end{tabular}

\subsection{Microstructure Characterization}

The morphology and structure of different phases and their interfaces was investigated by transmission electron microscopy (TEM) using either a JEOL JEM-2500SE instrument (JEOL Ltd., Tokyo, Japan) at University of California, Davis (UCD), or a FEI monochromated F20 UT Tecnai scanning transmission electron microscope (FEI Company, Hillsboro, OR) at the National Center for Electron Microscopy (NCEM). Scanning transmission electron microscopy (STEM) was carried out with a Titan G2 80-200 instrument (FEI Company, Hillsboro, OR) equipped with ChemiSTEM technology and a Fischione high angle angular dark field (HAADF) detector (Fischione, Export, PA) at the FEI Nanoport (Hillsboro, OR). All microscopes were operated at $200 \mathrm{kV}$.

Electron-transparent TEM samples were prepared with either a FEI Versa 3D focused ion beam (FIB) at the FEI Nanoport, or a FEI Scios FIB at UCD. The starting voltage was $30 \mathrm{kV}$ for trenching and initial thinning. The accelerating voltage of the ion beam was then reduced to 5 $\mathrm{kV}$ when sample thickness reached approximately $400 \mathrm{~nm}$. Final thinning was performed at $2 \mathrm{kV}$ when the TEM lamellae became electron-transparent. After final thinning, an ion beam energy of $0.5 \mathrm{kV}$ was used to remove most of the remaining amorphous damage layers from the sample surfaces. The final thickness of the TEM samples was approximately $60 \mathrm{~nm}$. 


\subsection{Chemical Composition Characterization}

Elemental distribution maps were acquired using an FEI Super-X windowless EDXS detector (FEl Company, Hillsboro, OR) installed on the Titan G2 80-200 instrument described above. Quantitative EDXS analysis was performed using the standardless technique for which CliffLorimer coefficients were calculated based on ionization cross-sections and the specific detector geometries [27]. EELS line scans and energy-loss near-edge fine structures (ELNES) were recorded with a Gatan Tridiem parallel electron energy loss spectrometer attached to the aberration corrected JEOL JEM 2100F/Cs scanning transmission electron microscope at UCD, and the monochromated Tecnai F20 UT instrument at NCEM. The monochromator was set in "unfiltered mode", which resulted in an energy resolution of approximately $0.5 \mathrm{eV}$ as measured by the full-width at half maximum of the zero-loss peak.

Multivariate statistical analysis (HREM Research Inc., Japan) was used to reduce random noise from as-acquired EELS data using principle component analysis. Acquired spectrum images were decomposed into eigenspectra with assigned eigenvalues. EELS spectra were subsequently reconstructed by using only statistically relevant principal constituents $[28,29]$.

\subsection{Precession Assisted Electron Diffraction}

Precession assisted electron diffraction (PED) was used to study the crystalline orientation of the $\mathrm{Al}$ matrix near the $\mathrm{Al} / \mathrm{B}_{4} \mathrm{C}$ interface. The advantage of PED over electron backscattered diffraction is that the achievable spatial resolution is determined by the diameter of the converged electron beam rather than by the detector-specimen geometry during SEM. Detailed information regarding the specifics and underlying physics of this technique are 
reported elsewhere [30-33]. PED was performed using a Phillips CM300 transmission electron microscope (FEI Company, Hillsboro, OR) equipped with the NanoMEGAS Digistar hardware controlled by the Topspin ${ }^{\mathrm{TM}}$ precession control platform (AppFive LLC, Arizona) at Lawrence Livermore National Laboratory. The microscope was operated at $300 \mathrm{kV}$.

\section{Results}

\subsection{Microstructure identification}

Fig. 1a shows a typical TEM bright field image of the 5083 AA trimodal composite in which the $\mathrm{B}_{4} \mathrm{C}$, UFG Al and CG Al regions are labeled. The dashed curve marks the interface between a CG region and an UFG region. The UFG regions generally show darker contrast when compared to $C G$ regions due to the fact that smaller grain size allows for stochastically oriented grains, and, hence, variations in dynamical diffracting conditions. $\mathrm{B}_{4} \mathrm{C}$ particles reveal a faceted morphology and are mostly distributed throughout the UFG regions. The observed distribution of $\mathrm{B}_{4} \mathrm{C}$ particles is caused by their addition to UFG regions during cryomilling, which leads to limited contact with CG regions that were introduced after cryomilling [22]. Fig. 1b shows a SEM micrograph at lower magnification that provides more detailed information about the distribution of CG Al, UFG $\mathrm{Al}$ and $\mathrm{B}_{4} \mathrm{C}$ particles within the $5083 \mathrm{AA}$ trimodal composite. SEM characterization reveals the $\mathrm{B}_{4} \mathrm{C}$ particles with relative dark contrast and confirms that they are embedded in UFG regions. CG regions exhibit no $\mathrm{B}_{4} \mathrm{C}$ particles over large areas of the microstructure. Fig. $1 \mathrm{~b}$ also demonstrates that $\mathrm{B}_{4} \mathrm{C}$ particles are distributed within the UFG regions that are clearly separated from the CG regions. The high aspect ratio of CG and UFG regions is a result of the extrusion process with a direction indicated by the arrow in Fig. 1b. 


\subsection{Interface composition and structures}

Fig. 2a shows a $\mathrm{B}_{4} \mathrm{C}$ particle in contact with $\mathrm{CG}$ Al on one side (Interface 1 ) and UFG Al at interfaces 2-4. Local chemical compositions and segregation behavior at interfaces were determined by EDXS analysis. The resulting elemental distribution maps for $\mathrm{Mg}, \mathrm{Al}, \mathrm{B}, \mathrm{C}$, and Fe are shown in Fig. $2 b-g$, respectively. The distribution of $\mathrm{Mn}$ directly correlates with that of Fe. Fig. $2 \mathrm{~b}$ demonstrates prominent segregation of $\mathrm{Mg}$ at Interface 1 between $\mathrm{B}_{4} \mathrm{C}$ and $\mathrm{CG} \mathrm{Al}$; such segregation of $\mathrm{Mg}$ also exists for interfaces between $\mathrm{B}_{4} \mathrm{C}$ and UFG $\mathrm{Al}$ (Interfaces 2 and 3) with weaker signal and a more diffuse contrast for $\mathrm{Mg}$. For Interface 4 there is no obvious sign of $\mathrm{Mg}$ segregation. Other interfaces surrounding smaller $\mathrm{B}_{4} \mathrm{C}$ grains in Fig. 2 show similar trends for Mg segregation. The elemental map in Fig. 2c shows a homogeneous distribution of Al, while Mg-rich layers observed in Fig. $2 b$ appear depleted in Al. The elemental distribution maps for B and $C$ in Figs. $2 d$ and $2 e$, respectively, confirm the identity of the large $B_{4} C$ grain. Distributions of Fe and $\mathrm{Mn}$ are shown in Fig. $2 \mathrm{f}$ and $2 \mathrm{~g}$ reveal that Fe and $\mathrm{Mn}$ are confined to small dispersoids randomly distributed throughout the microstructure. Fig. 3 shows elemental distribution maps for $\mathrm{Al}, \mathrm{Mg}, \mathrm{B}$, and $\mathrm{C}$ obtained from EDXS data acquired at higher magnification from the marked area of Interface 1 (see Fig. 2a). The elemental maps confirm the presence of a layered interface structure with Al signals (Fig. 3a) recorded from the area between the $\mathrm{B}_{4} \mathrm{C}$ particle and the Mg-rich layer (Fig. 3b). For the Al-rich interface layer quantitative EDXS analysis using the standardless Cliff-Lorimer method [27] reveals an Al/O atomic ratio of $1.47 \pm 0.29$. Consistent with Fig. 2 the location of the $\mathrm{B}_{4} \mathrm{C}$ particle is identified from B (Fig. 3c) and C signals (Fig. 3d). Fig. 3d also reveals the presence of carbon within the Alrich layer adjacent to the $\mathrm{B}_{4} \mathrm{C}$ particle. 
For a more detailed analysis of the interface morphologies, diffraction contrast bright field TEM images were recorded from all areas around the central $B_{4} C$ grain in Fig. 2. Fig. 4 shows a composite micrograph in which the individual TEM images were merged through maximizing the cross-correlation functions of the respective image overlap regions. The locations of Interfaces 1 through 4 are marked in the inset in the center of Fig. 4 . Interface 1 reveals the contact between $\mathrm{CG} \mathrm{Al}$ and the $\mathrm{B}_{4} \mathrm{C}$ particle. A significant number of areas with dark contrast are observed in the CG region indicating the presence of dislocations. The arrow in Fig. 4 marks a site where the Mg segregation layer transitions from a straight line to a curved morphology (cf. Fig. 2b). The straight dashed line is the $C G A l / B_{4} C$ interface, while the dashed curve marks an interface between the CG and UFG regions. The Mg-rich layer shows uniform thickness and accommodates the shape of the CG Al. Interfaces 2 and 4 are curved UFG $\mathrm{Al} / \mathrm{B}_{4} \mathrm{C}$ interfaces, while Interface 3 is a straight UFG $\mathrm{Al} / \mathrm{B}_{4} \mathrm{C}$ interface that is parallel to Interface 1 . A brief summary of morphologies and structures of Interfaces 1 through 4 is listed in Table 2.

Table 2. Summary of interfacial morphologies and structures.

\begin{tabular}{|c|c|c|c|c|}
\hline & Interface 1 & Interface 2 & Interface 3 & Interface 4 \\
\hline Morphology & Straight & Curved & Curved & Curved \\
\hline Configuration & $\begin{array}{c}\mathrm{UFG} / \mathrm{B}_{4} \mathrm{C} \text { (top), } \\
\mathrm{CG} / \mathrm{B}_{4} \mathrm{C} \text { (bottom) }\end{array}$ & UFG/B $\mathrm{B}_{4} \mathrm{C}$ & $\mathrm{UFG} / \mathrm{B}_{4} \mathrm{C}$ & $\mathrm{UFG} / \mathrm{B}_{4} \mathrm{C}$ \\
\hline Mg segregation & Strong & Weak, diffuse & Weak, diffuse & None \\
\hline
\end{tabular}


The structure and morphology of the double-layered structure between $\mathrm{B}_{4} \mathrm{C}$ and $\mathrm{CG} \mathrm{Al}$ (cf. Fig. 2 and 3) was further investigated by HRTEM. Micrographs recorded at medium resolution (Fig. 5a) and the HRTEM micrograph in Fig. 5b both show significant variations in layer thickness. The width of the interface varies between 20 and $25 \mathrm{~nm}$. Fig. $5 \mathrm{c}$ shows that the Mg-rich layer is polycrystalline. Different grains are outlined with dashed markings. The thickness of the Mg-rich layer is approximately $18 \pm 4 \mathrm{~nm}$. Measurements of lattice spacing from several different grains are consistent with those for $\mathrm{MgO}$ (e.g., $d_{(200)}=2.01 \pm 0.01 \AA$ in Fig. $5 \mathrm{c}$ and $d_{(111)}=2.31 \pm 0.05 \AA$ in Fig. 5d) [34]. As shown in Fig. 5c and 5d, the HRTEM contrast suggests the presence of an additional amorphous region between the $\mathrm{Mg}$ segregation layer and the $\mathrm{B}_{4} \mathrm{C}$ particle. That amorphous layer's (marked by dashed markings) thickness varies between 2 and $6 \mathrm{~nm}$. The observation of this amorphous layer is consistent with previous studies on trimodal Al systems $[8,17,22]$.

For a more detailed analysis of the local chemical composition, EELS intensity line profiles were recorded across Interfaces 1 and 2. Fig. 6a shows the integrated EELS intensity across the $\mathrm{CG} \mathrm{Al} / \mathrm{B}_{4} \mathrm{C}$ interface (Interface 1 ) as a function of relative distance. In the direction from the $\mathrm{CG} \mathrm{Al}$ to $\mathrm{B}_{4} \mathrm{C}$ particle, the $\mathrm{Al}$ K-edge $\mathrm{EELS}$ intensity drops significantly to a minimal value at a relative distance of approximately $13 \mathrm{~nm}$ and shows a local maximum value of approximately $24 \mathrm{~nm}$, the position of later Al peak coincides with that of the amorphous layer observed in Fig. 5. The signal extracted from the Mg K-edge, however, peaks at approximately $12.5 \mathrm{~nm}$ with a significantly wider full width at half maximum (FHWM) compared to that of the Al signal. In between the $\mathrm{CG} \mathrm{Al}$ and $\mathrm{B}_{4} \mathrm{C}$ phases, two peaks for the integrated $\mathrm{O}$ K-edge intensity are observed and coincide with the locations of the peaks observed for $\mathrm{Mg}$ and $\mathrm{Al}$, respectively. 
The EELS intensity profiles reproduce the EDXS data presented in Fig. 3. Chemical composition profiling therefore suggests that the amorphous layer is an oxide rich in Al, while the nanocrystalline layer is an Mg-rich oxide.

Fig. $6 \mathrm{~b}$ shows the integrated EELS intensity profiles for the UFG $\mathrm{Al} / \mathrm{B}_{4} \mathrm{C}$ interface (Interface 2 ). Between the UFG metal $\mathrm{Al}$ matrix and the $\mathrm{B}_{4} \mathrm{C}$ particle, multiple peaks of for $\mathrm{Mg}$ and $\mathrm{Al}$ intensities are observed. Where the $\mathrm{Mg}$ peak is at a maximum, the Al peak is at a minimum, and vice versa. The $\mathrm{O}$ signal reveals maximum intensities coinciding with the $\mathrm{Mg}$ signal only. However, the oxygen maximum intensity closest to the $\mathrm{B}_{4} \mathrm{C}$ grain reveals a shoulder at a relative distance of $125 \mathrm{~nm}$, which coincides with a maximum in the Al signal for the location where the Al matrix is in direct contact with the $\mathrm{B}_{4} \mathrm{C}$ particle. This observation is consistent with the EDXS results presented above (Fig. $3 a$ and $\mathrm{b}$ ) and confirms the existence of an Al-rich oxide layer between the Mg-rich phase and $\mathrm{B}_{4} \mathrm{C}$ for the UFG $\mathrm{Al} / \mathrm{B}_{4} \mathrm{C}$ interface (Interface 2). Over extended distances, UFG $\mathrm{Al} / \mathrm{B}_{4} \mathrm{C}$ interfaces reveal multiple layers of nanocrystalline magnesium oxide between the metal matrix and the reinforcing particle.

The HRTEM micrograph in Fig. 7a was recorded from Interface 4 where UFG Al is in direct contact with $\mathrm{B}_{4} \mathrm{C}$ with no amorphous layer present. The corresponding EELS intensity line profiles in Fig. 7b reveal no Mg and O EELS intensities for this interface configuration.

The local bonding environment at the $\mathrm{CG} \mathrm{Al} / \mathrm{B}_{4} \mathrm{C}$ interface was investigated through ELNES of the $\mathrm{O}$ K-edge. Fig. $8 \mathrm{a}$ and $8 \mathrm{~b}$ show the as-acquired $\mathrm{O}$ K-edge ELNES obtained from the Mgrich layer and from the amorphous layer adjacent to the $\mathrm{B}_{4} \mathrm{C}$ particle, respectively. The experimental spectra were recorded with an energy dispersion of $0.3 \mathrm{eV} /$ channel and are 
compared to reference spectra for $\mathrm{Al}_{2} \mathrm{O}_{3}$ and $\mathrm{MgO}$ [35]. Direct comparison of the experimental spectra with the corresponding reference data show good agreement with respect to the number, energy, and approximate relative intensity of the individual ELNES features. Hence, the EELS analysis confirms that the amorphous layer adjacent to the $\mathrm{B}_{4} \mathrm{C}$ particle consists of $\mathrm{Al}$ oxide $\left(\mathrm{Al}_{\mathrm{x}} \mathrm{O}_{\mathrm{y}}\right)$ and the Mg-rich layer is comprised of $\mathrm{MgO}$. Fig. 8c shows the spatially resolved EELS spectra recorded from the $\mathrm{B}_{4} \mathrm{C}$ particle and the amorphous $\mathrm{Al}_{\mathrm{x}} \mathrm{O}_{\mathrm{y}}$ layer that was identified by HRTEM in Fig. 5. No B was detected form the interface layer, while the $\mathrm{O} \mathrm{K}$ and $\mathrm{C}$ K-edge reveal statistically significant spectral intensities.

\subsection{Crystalline orientation near interface}

PED mapping was performed for the UFG $\mathrm{Al} / \mathrm{B}_{4} \mathrm{C}$ interface (Interface 2 ) to evaluate whether the interface morphology may correlate with any texturing in the UFG area. Fig. 9a shows an HAADF STEM image of the same area discussed above, with an orientation map extracted from the PED analysis overlaid on the STEM image. Diffraction signals recorded from the $\mathrm{B}_{4} \mathrm{C}$ particle and the $\mathrm{MgO}$ layer were removed from the results for ease of analysis and better presentation. The color-coded orientation map reveals no preferred orientation of the grains in the UFG region with respect to the $\mathrm{B}_{4} \mathrm{C}$ particle. For a more detailed analysis, $\left.\left.<001\right\rangle,<110\right\rangle$ and $\left.<111\right\rangle$ pole figures of the area mapped in Fig. 9a are plotted in Fig. 9b and show no dominant texture of the metallic matrix in the vicinity of the $\mathrm{B}_{4} \mathrm{C}$ particle. 


\section{Discussion}

\subsection{Interfacial structure and composition}

The experimental results obtained in this study reveal a 2-6 nm thick amorphous layer with $\mathrm{Al}_{\mathrm{x}} \mathrm{O}_{\mathrm{y}}$ composition surrounding the $\mathrm{B}_{4} \mathrm{C}$ particles, and the presence of one or multiple polycrystalline MgO layer(s) separating the amorphous layer from the CG or UFG metal matrix, respectively. Quantitative EDXS analysis suggests that such amorphous aluminum oxide layers are non-stoichiometric and enriched with Al. The relative atomic ratio of $1.47 \pm 0.29$ is consistent with earlier reports by Jeurgens et al. [34]. It was previously assumed that the amorphous layer originates from surface oxidization of 5083 AA during processing and handling of the $5083 \mathrm{AA}$ powder [37]. However, crystalline $\mathrm{B}_{4} \mathrm{C}$ may undergo amorphization under high strain rate deformation, as it was shown under shock loading in ballistic tests [23], or during nanoindentation [37]. Cryomilling may have similar impact and could lead to the formation of the observed amorphous layer discussed above. The C K-ELNES is sensitive to detect amorphous $\mathrm{B}_{4} \mathrm{C}$ by the presence of $\mathrm{a} \pi^{*}$ excitation at the edge onset $[23,37,38]$. Fig. $8 \mathrm{c}$, however, demonstrates that no B K-edge signal was detected from the amorphous oxide layer. Hence, the EELS analysis in consistent with the EDXS results presented in Fig. 3 and confirms the predicted surface oxidization of aluminum rather than amorphization of boron carbide. The presence of carbon in the amorphous oxide layer stems from the use of steric acid during cryomilling.

The combination of HRTEM imaging and chemical composition profiling revealed that each Mg-rich layer is comprised of polycrystalline $\mathrm{MgO}$ with a thickness of approximately $20 \mathrm{~nm}$ (Fig. 
6). This result suggests that the previously observed nanocrystalline layers between $\mathrm{B}_{4} \mathrm{C}$ and the UFG Al matrix [8,22] are of $\mathrm{MgO}$ composition rather than nanocrystalline $\mathrm{Al}$ grains. This conclusion was derived from the following three observations: firstly, the location of the Mgrich grains between the $\mathrm{B}_{4} \mathrm{C}$ reinforcement and the UFG Al matrix is identical that of what was previously described as nanocrystalline Al grains; secondly, the size of the Mg-rich grains (approximately $20 \mathrm{~nm}$ ) is consistent with the size of what was previously described as nanocrystalline Al grains, which is finer than the size of the UFGs that result after cryomilling plus thermo-mechanical consolidation; thirdly, typically 2-4 layers of nanocrystalline Al grains had been reported to be present between the $\mathrm{B}_{4} \mathrm{C}$ particles and the UFG Al matrix, which agrees with the EELS observations of four layers of Mg-rich grains, as shown in Fig. 6 b.

The amorphous $\mathrm{Al}_{x} \mathrm{O}_{y}$ layer, although not directly observed at the UFG $\mathrm{Al} / \mathrm{B}_{4} \mathrm{C}$ interface due to the projection view in TEM experiments, always separates the nanocrystalline $\mathrm{MgO}$ from the $\mathrm{B}_{4} \mathrm{C}$ grains (see EELS profiles in Fig. 6). Therefore, $\mathrm{MgO}$ is never in direct contact with the $\mathrm{B}_{4} \mathrm{C}$ reinforcements.

\subsection{Amorphous $\mathrm{Al}_{x} \mathrm{O}_{y}$ and nanocrystalline $\mathrm{MgO}$}

The oxidation of metallic aluminum and the formation of native oxide surface layers is almost unavoidable during processing as the standard formation enthalpy for $\mathrm{Al}_{2} \mathrm{O}_{3}$ is -1675.7 $\mathrm{kJ} / \mathrm{mol}[40]$. An unrealistic oxygen partial pressure at or below $10^{-143}$ Torr is required to avoid oxidization of clean Al [41]. Hence, the oxidation products in the trimodal composite can be traced to four possible sources. First, the feedstock metal powders utilized for this study typically contain surface oxide layers, which stabilize the powders during atomization [41]. 
Second, during cryomilling, the powder particles are continuously fragmented and new clean Al surfaces are created. A turbulent mixing process during cryomilling was adopted for our experiments to allow boiling $\mathrm{N}_{2}$ to escape, but this also introduces oxygen that leads to oxidization of the newly created clean Al surfaces. Third, whereas the as-cryomilled powder is stored in a glove box maintained under an argon atmosphere, the prevalent oxygen partial pressure is also sufficient to allow for further oxidization of clean Al powder surfaces. Fourth, another source for the observed $\mathrm{Al}_{\mathrm{x}} \mathrm{O}_{\mathrm{y}}$ is the reaction of $\mathrm{Al}$ with water vapor that is generated during the degassing process. [26,42]. Water vapor originates from chemisorbed water on prior $\mathrm{Al}_{\mathrm{x}} \mathrm{O}_{\mathrm{y}}$ surfaces, and from physisorbed water on the Al powder surface.

Amorphous $\mathrm{Al}_{x} \mathrm{O}_{y}$ layers have the potential to crystallize to $\gamma-\mathrm{Al}_{2} \mathrm{O}_{3}$ at elevated temperatures $[36,43]$. However, no crystalline $\mathrm{Al}_{2} \mathrm{O}_{3}$ was observed in the trimodal microstructures investigated in this study. The transition from amorphous to crystalline aluminum oxide is debated in the literature. For oxide film thickness below $4 \mathrm{~nm}$ the amorphous phase is commonly sub-stoichiometric in oxygen $\left(\mathrm{Al}_{\mathrm{x}} \mathrm{O}_{\mathrm{y}}\right)$ and is thermodynamically more stable than the crystalline state $\left(\mathrm{Al}_{2} \mathrm{O}_{3}\right)[36,43]$. However, no universal agreement exists on the critical thickness for the structural transition, which is dependent on multiple parameters, including the crystalline orientation of the Al surface, the partial pressure of oxygen, the particle size of Al, and temperature [44-46]. Crystalline transitions into $\mathrm{Al}_{2} \mathrm{O}_{3}$ require growth of native amorphous $\mathrm{Al}_{\mathrm{x}} \mathrm{O}_{\mathrm{y}}$ to reach both a critical thickness and correct stoichiometry in the presence of oxygen and elevated temperatures [36]. During this study both conditions are only satisfied during the degassing process with limited oxygen concentrations from the decomposition of water vapor and surfactants left after cryomilling. Thus, with limited oxygen available during the degassing 
process and oxygen from $\mathrm{Al}_{x} \mathrm{O}_{y}$ being continuously consumed to form $\mathrm{MgO}$, it is more likely for $\mathrm{Al}_{x} \mathrm{O}_{y}$ to grow non-stoichiometrically and maintain an amorphous structure. The observed presence of carbon within the $\mathrm{Al}_{x} \mathrm{O}_{y}$ layer (cf. Fig. $3 d$ ) is due to the remaining free carbon that originates from surfactants added during cryomilling [26].

The experimental results reveal $\mathrm{Mg}$ segregation to the surface of the Al grains and the formation of nanocrystalline $\mathrm{MgO}$ between the metal matrix grains and the amorphous oxide layer. The standard formation enthalpy for $\mathrm{MgO}$ is $-601.6 \mathrm{~kJ} / \mathrm{mol}$ [40]. Hence, $\mathrm{MgO}$ is thermodynamically more stable than $\mathrm{Al}_{2} \mathrm{O}_{3} . \mathrm{Mg}$ atoms present inside the $\mathrm{Al}$ grains near the surface will locally consume oxygen from the amorphous $\mathrm{Al}_{x} \mathrm{O}_{y}$ to form $\mathrm{MgO}$. This mechanism causes a depletion of metallic $\mathrm{Mg}$ in surface regions within the metal matrix and thus creates a driving force for segregation of $\mathrm{Mg}$ towards the grain surfaces. Fig. 10 shows a schematic diagram of $\mathrm{Mg}$ segregation that leads to the formation of the observed nanocrystalline $\mathrm{MgO}$ interface layer. Previous studies have shown that such diffusion of $\mathrm{Mg}$ can lead to the formation of $\mathrm{MgO}, \mathrm{MgAl}_{2} \mathrm{O}_{4}$ or a mixture of the two on the surface of the aluminum alloy $[47,48]$. However, the ELNES results in Fig. 8 show no sign of any spectral features that are characteristic for the $\mathrm{MgAl}_{2} \mathrm{O}_{4}$ spinel structure [49]. Formation of $\mathrm{MgAl}_{2} \mathrm{O}_{4}$ requires additional oxygen compared to the formation of $\mathrm{MgO}$ and can therefore be neglected.

PED shows that there is no dominant texture in the Al matrix near the Mg-rich layer. It is therefore concluded that the formation of $\mathrm{MgO}$ is independent of the orientation and surface energy of the Al grains. Fig. $2 \mathrm{~b}$ and Fig. 4 show that the polycrystalline layer of $\mathrm{MgO}$ accommodates the shape of the CG region at Interface 1(with UFG region separating the MgO 
layer from the $\mathrm{B}_{4} \mathrm{C}$ particle). From this observation it is concluded that the segregation behavior for $\mathrm{Mg}$ and subsequent formation of $\mathrm{MgO}$ is directly related to the presence of amorphous $\mathrm{Al}_{2} \mathrm{O}_{3}$ on the surface of $\mathrm{CG} \mathrm{Al}$ and is not affected by the crystal orientation of $\mathrm{B}_{4} \mathrm{C}$ particles. This interpretation is consistent with the observation that no $\mathrm{Mg}$ segregation is observed in the absence of any surface aluminum oxides (cf. Fig. 7).

The interfaces between $\mathrm{CG} A \mathrm{Al}$ regions and $\mathrm{B}_{4} \mathrm{C}$ particles exhibit a single layer of $\mathrm{MgO}$ while UFG Al/ $\mathrm{B}_{4} \mathrm{C}$ interfaces reveal multiple layers of $\mathrm{MgO}$. This is due to the fact that UFG Al regions have more grain boundary area that not only provides more $\mathrm{Al}_{2} \mathrm{O}_{3}$ interface area but also more diffusion pathways for the formation of $\mathrm{MgO}$ (cf. Fig. 10).

\subsection{Interfacial properties}

Metal/ceramic interfaces in metal matrix composites such as $\mathrm{Al} / \mathrm{B}_{4} \mathrm{C}$ are often characterized by relatively weak bonding between the different constituents [50]. The absence of pores or voids from the $\mathrm{Al} / \mathrm{B}_{4} \mathrm{C}$ interfaces could be attributed to the wetting behavior of amorphous aluminum oxide at the ceramic particle surfaces. In contrast, a direct contact between crystalline $\mathrm{Al}$ grains and $\mathrm{B}_{4} \mathrm{C}$ particles would cause lattice mismatches at the metal/ceramic interface and, hence, an increase in the interface energy [22,51].

In related work, Vogt et al. observed cracks in the metal matrix that formed $100-200 \mathrm{~nm}$ away from the $\mathrm{Al} / \mathrm{B}_{4} \mathrm{C}$ interfaces in $5083 \mathrm{AA}$ trimodal composites during compression tests [13]. The size of the MgO grains of approximately $20-25 \mathrm{~nm}$, and the presence of multiple $\mathrm{MgO}$ layers between the UFG Al region and the $\mathrm{B}_{4} \mathrm{C}$ reinforcement particles is consistent with the distance between the observed location for crack initiation and the surface of the $\mathrm{B}_{4} \mathrm{C}$ particles. 
More detailed investigations, including in-situ TEM experiments, are required to determine whether the interface strength between the nanocrystalline MgO and the UFG Al matrix is considerably smaller than that between the other constituents in this trimodal system.

\section{Conclusions}

Two different interfacial structures have been observed at $\mathrm{Al} / \mathrm{B}_{4} \mathrm{C}$ interfaces in $5083 \mathrm{AA}$ trimodal composites: existence of an amorphous layer with a thickness ranging between 2 and $6 \mathrm{~nm}$, and the existence of nanocrystalline grains smaller in size than the grains in the bulk UFG Al regions). EDXS and EELS studies demonstrate that the amorphous layer consists of aluminum oxide, and that amorphous layer separates the $\mathrm{B}_{4} \mathrm{C}$ reinforcement particle from one or multiple layer(s) of nanocrystalline $\mathrm{MgO}$. The formation of $\mathrm{MgO}$ grains is due to the fact that $\mathrm{Mg}$ has a higher affinity for $\mathrm{O}$ than $\mathrm{Al}$ and diffuses toward the $\mathrm{Al}_{2} \mathrm{O}_{3}$ surface layer. No evidence was found for a correlation of the formation of $\mathrm{MgO}$ with the orientation of the $\mathrm{Al}$ matrix or the $\mathrm{B}_{4} \mathrm{C}$ reinforcement particles. The experimental results suggest that the presence of both amorphous aluminum oxide and at least one layer of nanocrystalline MgO improve the interfacial bonding and wetting capability of the $\mathrm{Al} / \mathrm{B}_{4} \mathrm{C}$ interfaces.

\section{Acknowledgements}

X.Z., J.F.R. and K.v.B. were financially supported by a University of California Laboratory Fee grant (\#12-LR-238313). J.M.S., T.H. and E.J.L received funding from the Office of Naval Research (program manager: Dr. Lawrence Kabacoff) under grant number N00014-12-1-0237. The FIB 
instrument at UC Davis was acquired with grant number N00014-13-1-0668 from Office of Naval Research (program manager: Dr. Lawrence Kabacoff). The precession electron diffraction experiments were performed under the auspices of the U.S. Department of Energy, Office of Basic Energy Sciences, Division of Materials Sciences and Engineering at Lawrence Livermore National Laboratory under Contract DE-AC52-07NA27344 and supported by FWP SCW0974 with equipment capabilities established under FWP SCW0939. We acknowledge support from the National Center for Electron Microscopy, Lawrence Berkeley National Lab, which is supported by the US Department of Energy under contract no. DE-AC02-05CH11231. X.Z. acknowledges Dr. Huikai Cheng and Dr. Jessica Riesterer (FEI Company) for their invaluable help during data acquisition at the FEI Nanoport.

\section{References}

[1] Hahn H, Padmanabhan KA. Nanostructured Mater 1995;6:191.

[2] Witkin DB, Lavernia EJ. Prog Mater Sci 2006;51:1.

[3] Moriarty P. Rep Prog Phys 2001;64:297.

[4] Koch CC. Nanostructured Mater 1993;2:109.

[5] Valiev R., Islamgaliev R., Alexandrov I. Prog Mater Sci 2000;45:103.

[6] Lu K, Lu J. Mater Sci Eng A 2004;375-377:38.

[7] Lucadamo G, Yang NYC, Marchi CS, Lavernia EJ. Mater Sci Eng A 2006;430:230.

[8] Yao B, Hofmeister C, Patterson T, Sohn Y, Bergh M van den, Delahanty T, Cho K. Compos Part Appl Sci Manuf 2010;41:933.

[9] Ma E. Scr Mater 2003;49:663.

[10] Legros, B. R. Elliott, M. N. Rittne M. Philos Mag A 2000;80:1017.

[11] Han BO, Lavernia EJ, Lee Z, Nutt S, Witkin D. Metall Mater Trans A 2005;36:957. 
[12] Zhao Y, Zhu Y, Lavernia EJ. Adv Eng Mater 2010;12:769.

[13] Vogt R, Zhang Z, Huskins E, Ahn B, Nutt S, Ramesh KT, Lavernia EJ, Schoenung JM. Mater Sci Eng A 2010;527:5990.

[14] Ye J, Han BQ, Lee Z, Ahn B, Nutt SR, Schoenung JM. Scr Mater 2005;53:481.

[15] Ye J, Han BQ, Schoenung JM. Philos Mag Lett 2006;86:721.

[16] Ye J, He J, Schoenung JM. Metall Mater Trans A 2006;37:3099.

[17] Li Y, Zhang Z, Vogt R, Schoenung JM, Lavernia EJ. Acta Mater 2011;59:7206.

[18] Vogt RG, Zhang Z, Topping TD, Lavernia EJ, Schoenung JM. J Mater Process Technol 2009;209:5046.

[19] Meyers MA. Mechanical Behavior of Materials, 2nd ed. Cambridge ; New York: Cambridge University Press; 2009.

[20] Zhang H, Ye J, Joshi SP, Schoenung JM, Chin ESC, Gazonas GA, Ramesh KT. Adv Eng Mater 2007;9:355.

[21] Zhang Z, Topping T, Li Y, Vogt R, Zhou Y, Haines C, Paras J, Kapoor D, Schoenung JM, Lavernia EJ. Scr Mater 2011;65:652.

[22] Li Y, Zhao YH, Ortalan V, Liu W, Zhang ZH, Vogt RG, Browning ND, Lavernia EJ, Schoenung JM. Mater Sci Eng A 2009;527:305.

[23] Chen M. Science 2003;299:1563.

[24] Hwang SJ, Fernandez C, Amoureux JP, Cho J, Martin SW, Pruski M. Solid State Nucl Magn Reson 1997;8:109.

[25] Li Y, Liu W, Ortalan V, Li WF, Zhang Z, Vogt R, Browning ND, Lavernia EJ, Schoenung JM. Acta Mater 2010;58:1732.

[26] Vogt R. Ultrafine-Grained Aluminm and Boron Carbide Metal Matrix Composites. [S.I.]: Proquest, Umi Dissertatio; 2011.

[27] J.I. Goldstein, J.L. Costley, G.W. Lorimer, S.J.B. Reed. Scan Electron Microsc 1977:315.

[28] Watanabe M, Okunishi E, Ishizuka K. Microsc Anal 2009:5.

[29] Chang C-H, Rufner JF, Benthem K van, Castro RHR. Chem Mater 2013;25:4262.

[30] Vincent R, Midgley PA. Ultramicroscopy 1994;53:271.

[31] Brons JG, Thompson GB. JOM 2014;66:165. 
[32] Avilov A, Kuligin K, Nicolopoulos S, Nickolskiy M, Boulahya K, Portillo J, Lepeshov G, Sobolev B, Collette JP, Martin N, Robins AC, Fischione P. Ultramicroscopy 2007;107:431.

[33] Gjønnes J, Hansen V, Kverneland A. Microsc Microanal 2004;10:16.

[34] 2014 International Centre for Diffraction Data-04-006-5939. n.d.

[35] Gatan EELS Atlas. Gatan Inc 2010.

[36] Jeurgens LPH, Sloof WG, Tichelaar FD, Mittemeijer EJ. Surf Sci 2002;506:313.

[37] Kim Y-W, Griffith WM, Froes FH. JOM 1985;37:27.

[38] Ge D, Domnich V, Juliano T, Stach E., Gogotsi Y. Acta Mater 2004;52:3921.

[39] Domnich V, Reynaud S, Haber RA, Chhowalla M. J Am Ceram Soc 2011;94:3605.

[40] Cox J, Wagman D, Medvedev V. CODATA Key Values for Thermodynamics. New York : Hemisphere Pub. Corp.,; 1989.

[41] Kowalski L, Korevaar BM, Duszczyk J. J Mater Sci 1992;27:2770.

[42] Zhang Z, Dallek S, Vogt R, Li Y, Topping TD, Zhou Y, Schoenung JM, Lavernia EJ. Metall Mater Trans A 2010;41:532.

[43] Jeurgens LP., Sloof W., Tichelaar F., Mittemeijer E. Thin Solid Films 2002;418:89.

[44] Trunov MA, Schoenitz M, Zhu X, Dreizin EL. Combust Flame 2005;140:310.

[45] Sánchez-López JC, González-Elipe AR, Fernández A. J Mater Res 1998;13:703.

[46] Jeurgens LPH, Sloof WG, Tichelaar FD, Mittemeijer EJ. J Appl Phys 2002;92:1649.

[47] Krizik P, Balog M, Illekova E, Svec P, Matko I, Stepanek M, Nosko M, Simancik F. J Mater Process Technol 2014;214:1165.

[48] Wakefield GR, Sharp RM. Appl Surf Sci 1991;51:95.

[49] Van Benthem K, Kohl H. Micron 2000;31:347.

[50] Clyne TW. An Introduction to Metal Matrix Composites. Cambridge [England]: New York, NY USA : Cambridge University Press; 1993.

[51] Benedictus R, Böttger A, Mittemeijer E. Phys Rev B 1996;54:9109. 


\section{$\underline{\text { Figure Captions }}$}

Fig. 1: (a) TEM image showing micro constituents of $C G$, UFG and $B_{4} C$ within trimodal system.

(b) SEM imaging of a TEM sample prepared by FIB showing the distribution of CG, UFG and $\mathrm{B}_{4} \mathrm{C}$ particles within the $5083 \mathrm{AA}$ trimodal composite. The extrusion direction is indicated by the white arrow.

Fig.2: (a) High-angle annular dark field STEM image showing a $\mathrm{B}_{4} \mathrm{C}$ particle located in the center of the image that is in contact with both a CG Al region at Interface 1 and UFG Al regions at Interfaces 2-4; EDXS maps illustrate the distribution of (b) $\mathrm{Mg}$, (c) Al, (d) B, (e) C, (f) Fe, and (g) Mn within the trimodal composite.

Fig.3: Elemental distribution maps recorded from the area labeled in Fig. 2a. Panels (a)-(d) show the respective elemental distribution maps obtained by EDXS for (a) Al, (b) Mg, (c) $B$, and (d) C.

Fig.4: Collage of bright field TEM images that were recorded around the B4C particle displayed in Figure 2. The dashed line marks the interface of $\mathrm{B}_{4} \mathrm{C}$ with the $\mathrm{CG} \mathrm{Al}$ matrix, and of the CG and UFG regions above the arrow.

Fig.5: (a) Bright field TEM image of the interface between the $\mathrm{B}_{4} \mathrm{C}$ particle and the $\mathrm{Al}$ matrix; (b) TEM image revealing the thickness of the Mg-rich layer; (c) HRTEM image showing a double-layered interface consists of amorphous layer and polycrystalline Mg-rich layer. The lattice spacing observed from the Mg-rich layer is $2.01 \pm 0.01 \AA$ for $(200)$ planes and 2.31 $\pm 0.05 \AA$ for (111) planes. (d) TEM image revealing the existence of an amorphous 
layer between the $\mathrm{B}_{4} \mathrm{C}$ and the Mg-rich layer with a thickness of varying between 3 and $6 \mathrm{~nm}$.

Fig.6: Integrated EELS intensities for the $\mathrm{K}$ edges of $\mathrm{Mg}, \mathrm{Al}, \mathrm{B}$, and $\mathrm{O}$ as a function of relative distance obtained from: (a) CG Al/B $\mathrm{B}_{4} \mathrm{C}$ (Interface 1) and (b) UFG Al/ $\mathrm{B}_{4} \mathrm{C}$ (Interface 2).

Fig. 7: (a) HRTEM micrograph of Interface 4 revealing a direct contact between the UFG Al and the $\mathrm{B}_{4} \mathrm{C}$. The dashed line highlights the location of the interface. (b) Integrated EELS intensities for the $\mathrm{K}$ edges of $\mathrm{Mg}, \mathrm{Al}, \mathrm{B}$, and $\mathrm{O}$ as a function of position obtained from Interface 4 .

Fig.8: (a) ELNES spectra showing Mg K-edges for MgO obtained from the Mg-rich layer compared to a reference spectrum for bulk MgO [34]. (b) Al K-edge obtained from the amorphous layer compared to a reference spectrum for bulk $\mathrm{Al}_{2} \mathrm{O}_{3}$ [35]. (c) EELS spectra of the $\mathrm{BK}, \mathrm{CK}$ and $\mathrm{OK}$ absorption edges recorded from the interior of the $\mathrm{B}_{4} \mathrm{C}$ particle and the amorphous $\mathrm{Al}_{x} \mathrm{O}_{y}$ layer. Spectra were recorded with a dispersion of 0.3 $\mathrm{eV} /$ channel.

Fig. 9: (a) Crystal orientation map obtained from PED that is overlaid onto an HAADF image of the same UFG $5083 \mathrm{AA} / \mathrm{B}_{4} \mathrm{C}$ interface. (b) shows the [001], [110], [111] pole figures extracted from PED measurements with no significant texture in the UFG region.

Fig. 10: Sketch illustrating the formation of nanocrystalline MgO layers that surround the observed $\mathrm{B}_{4} \mathrm{C}$ reinforcement particle. 
Figure 01

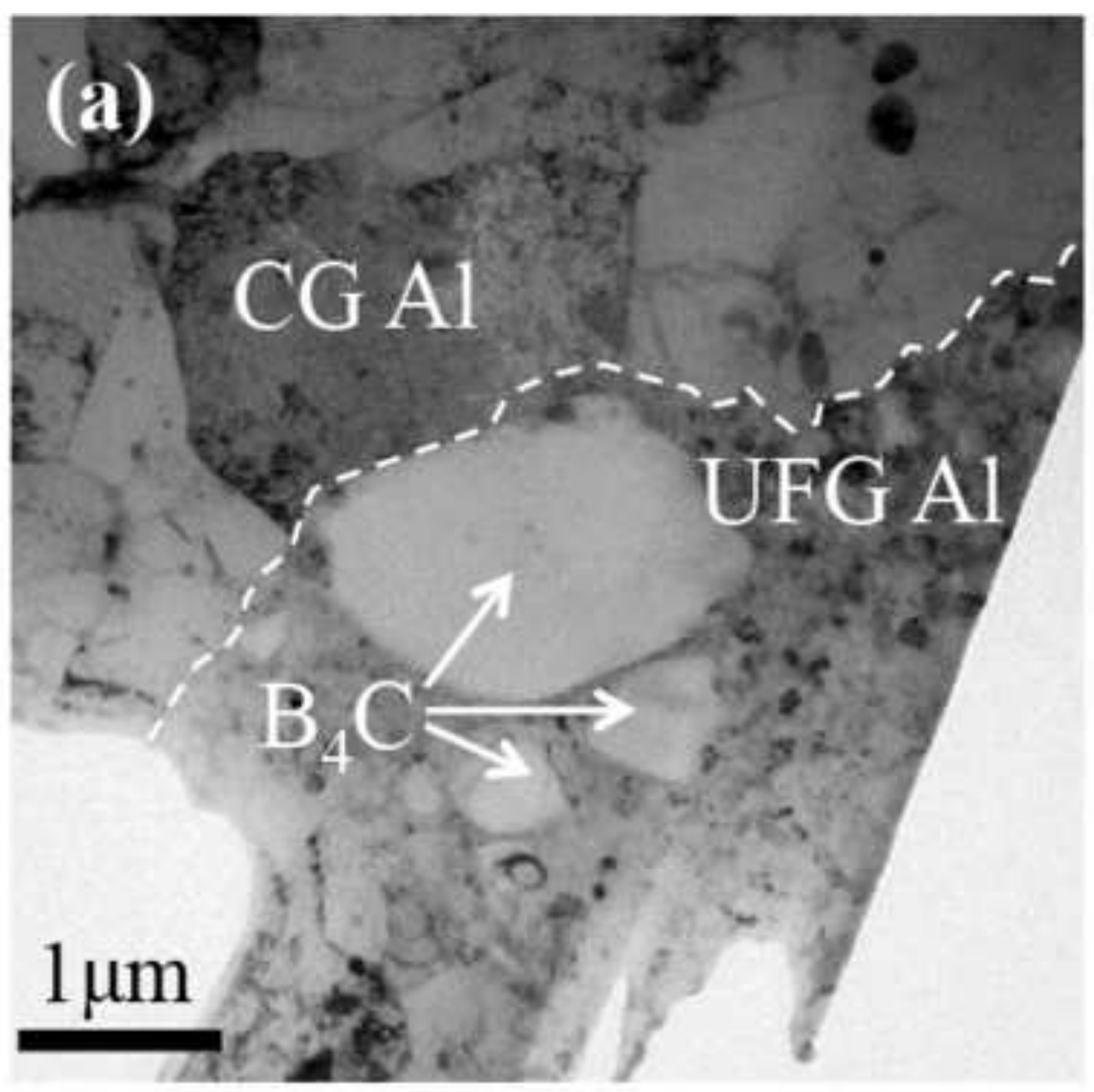

\section{(b)}

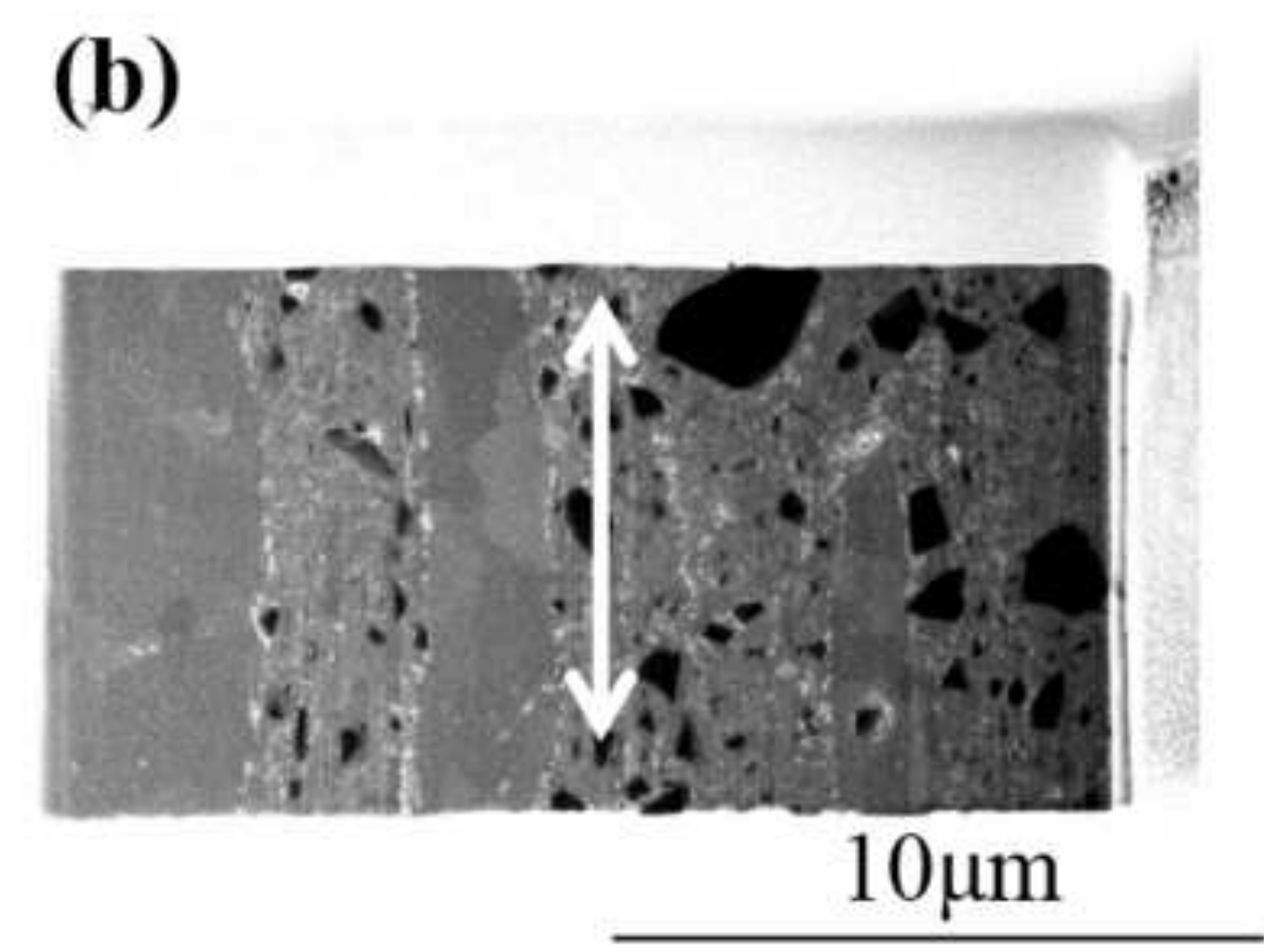

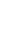


Figure 02
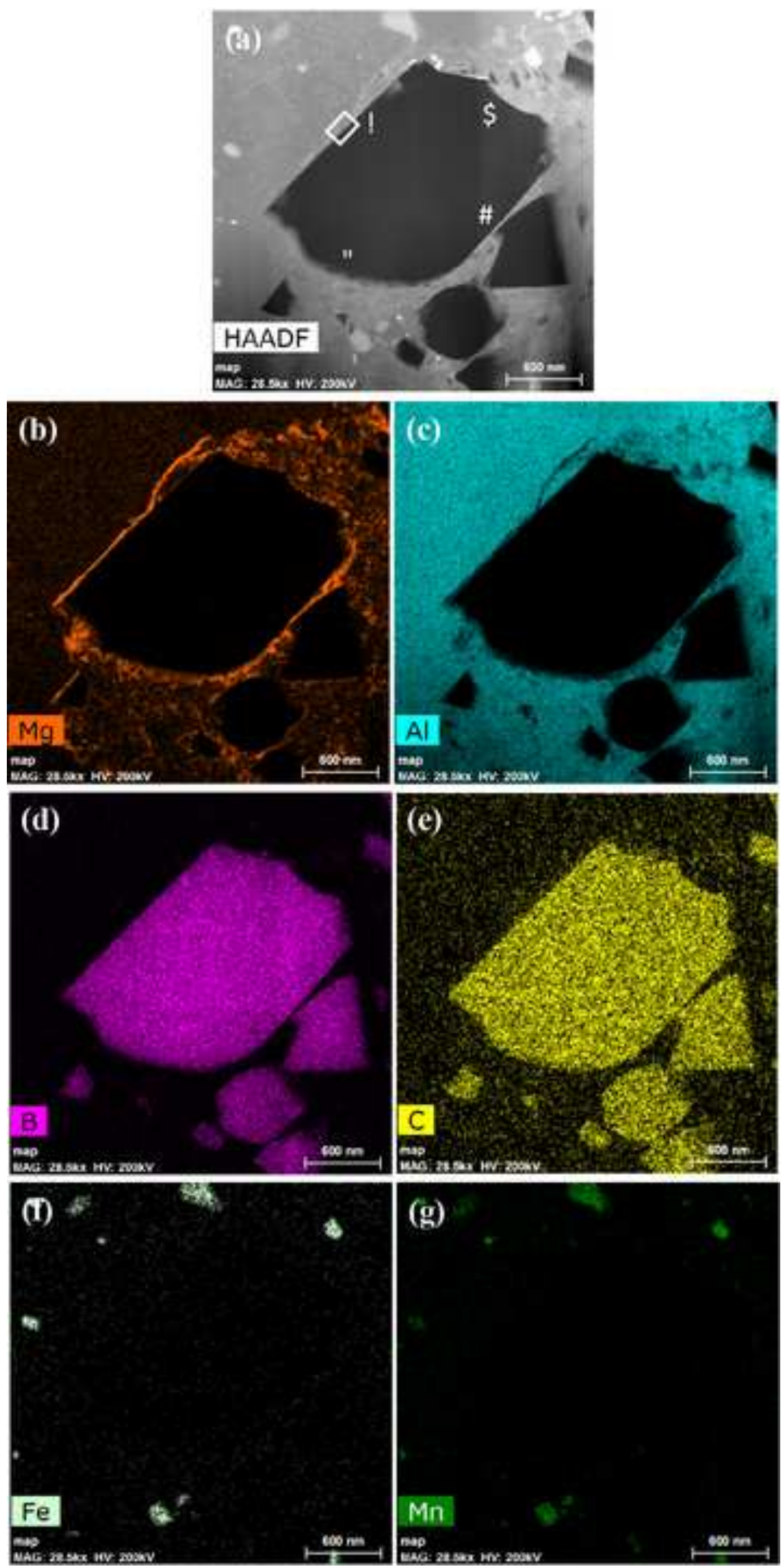

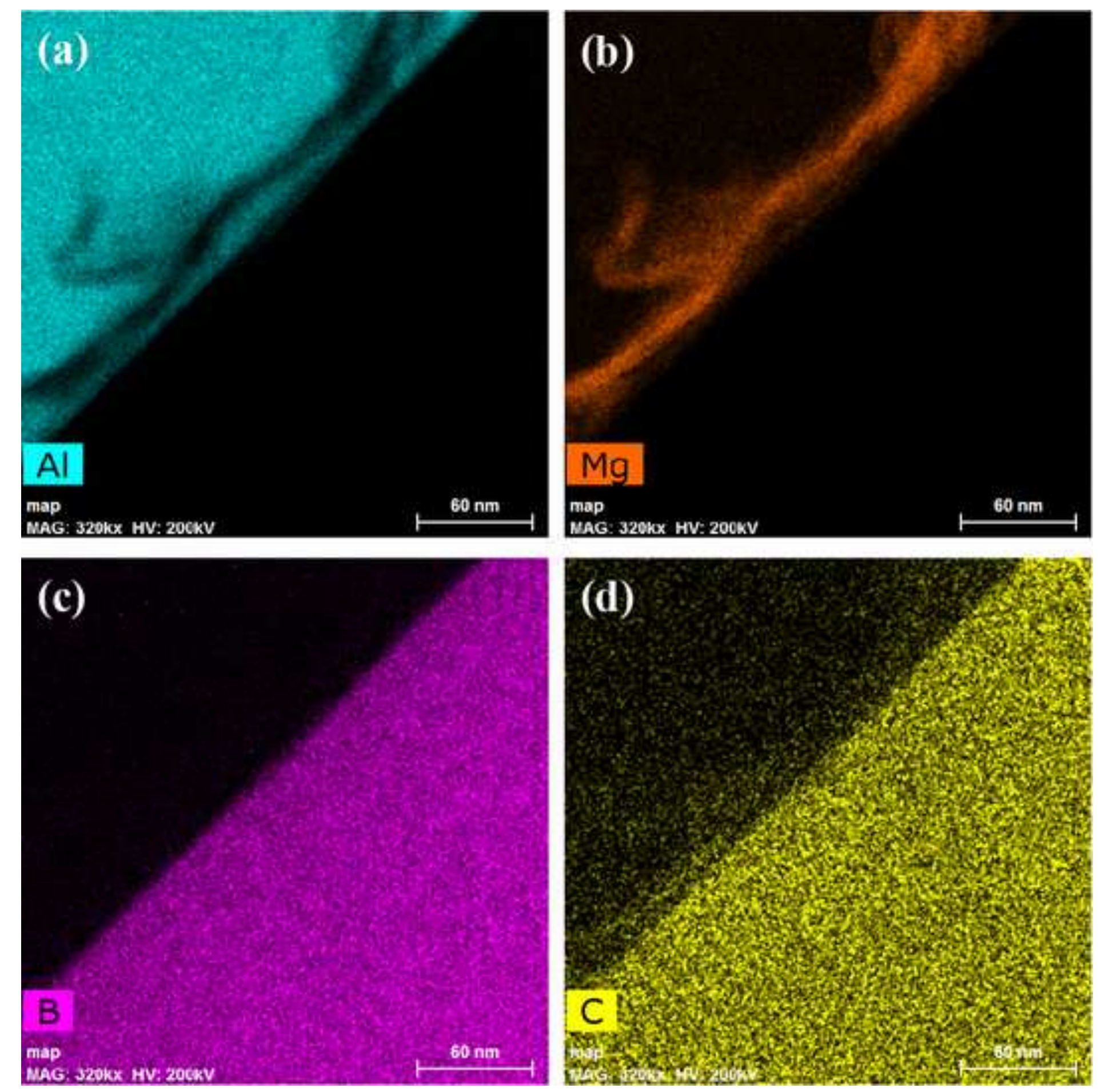


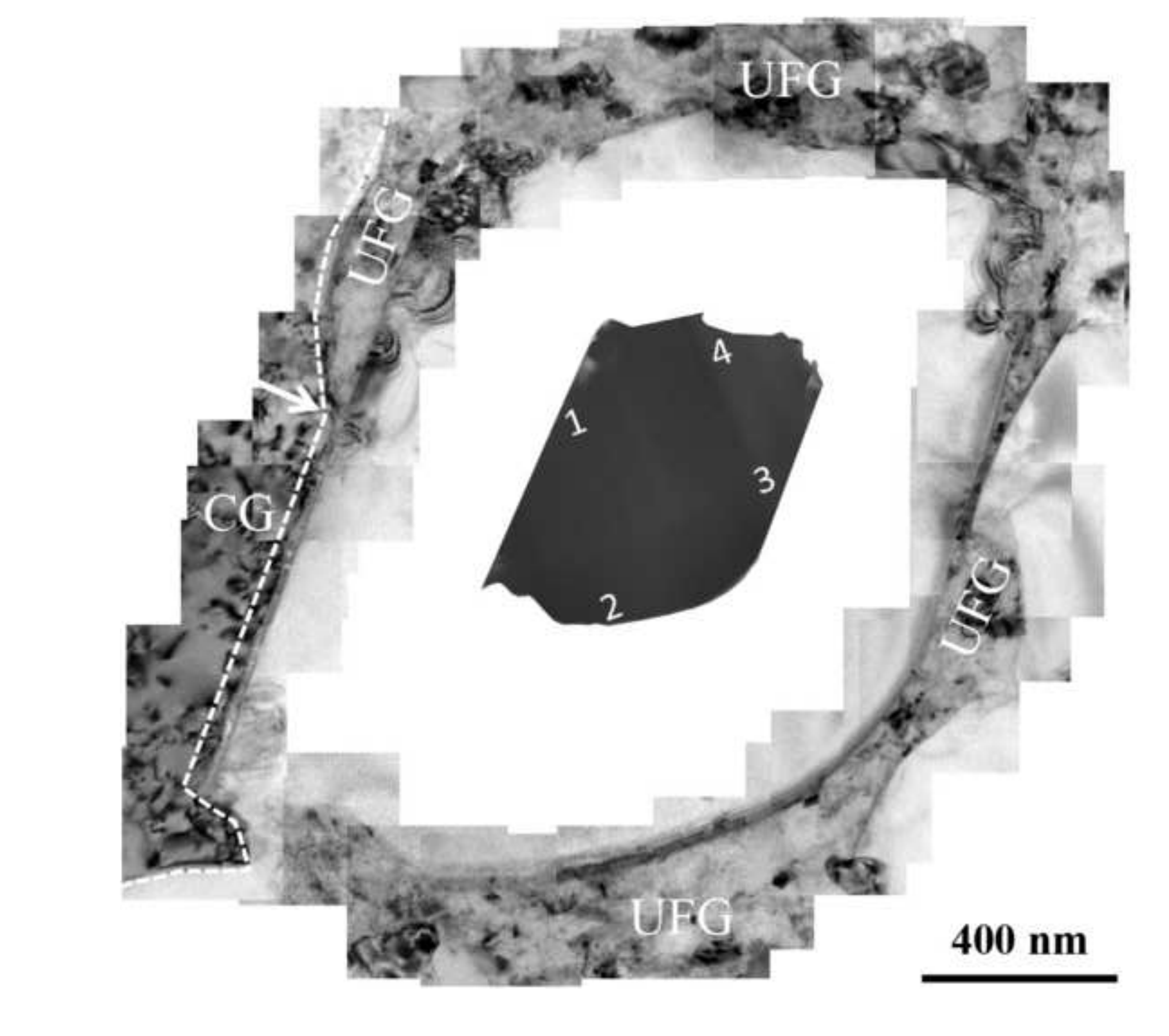

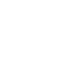



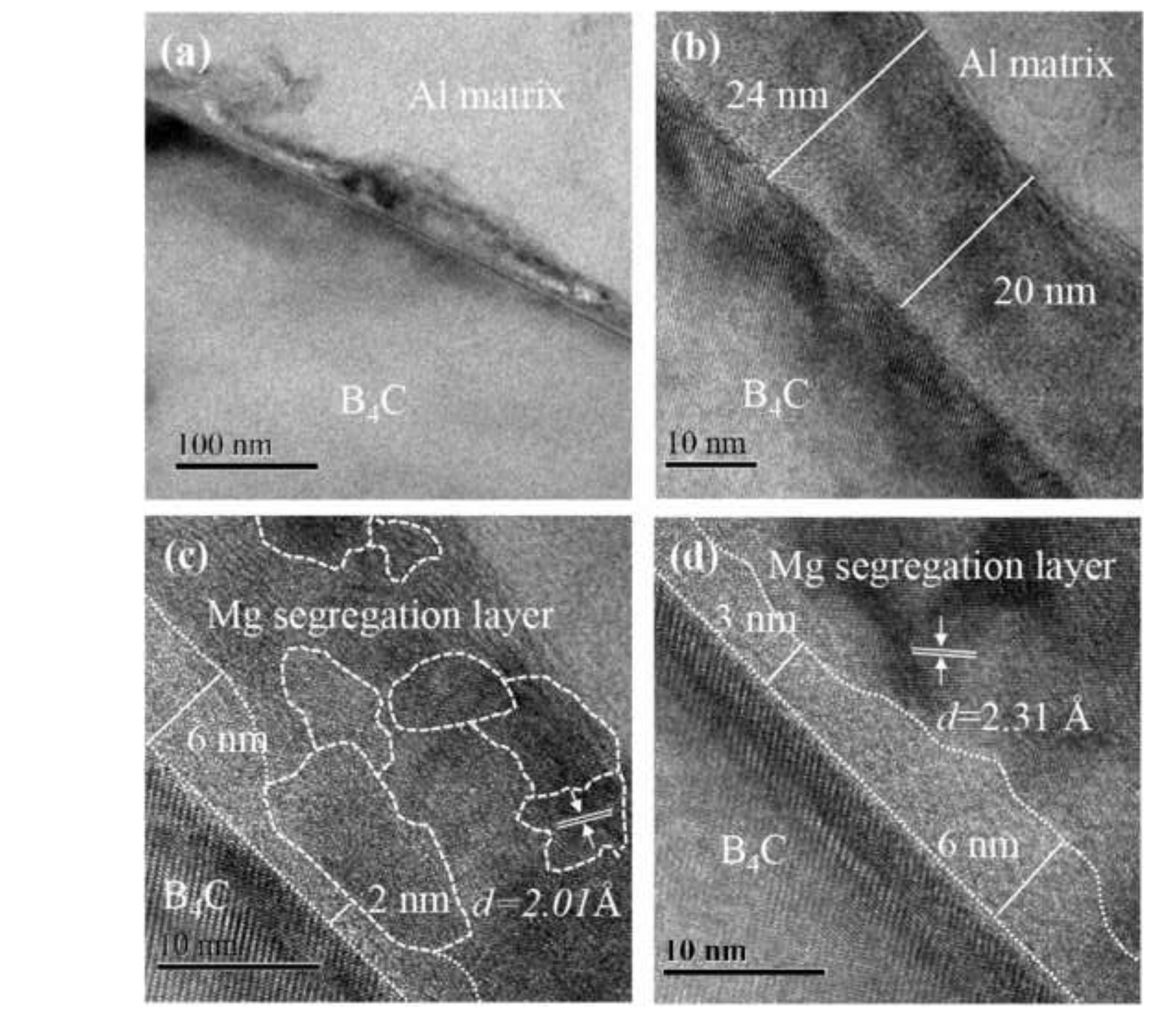

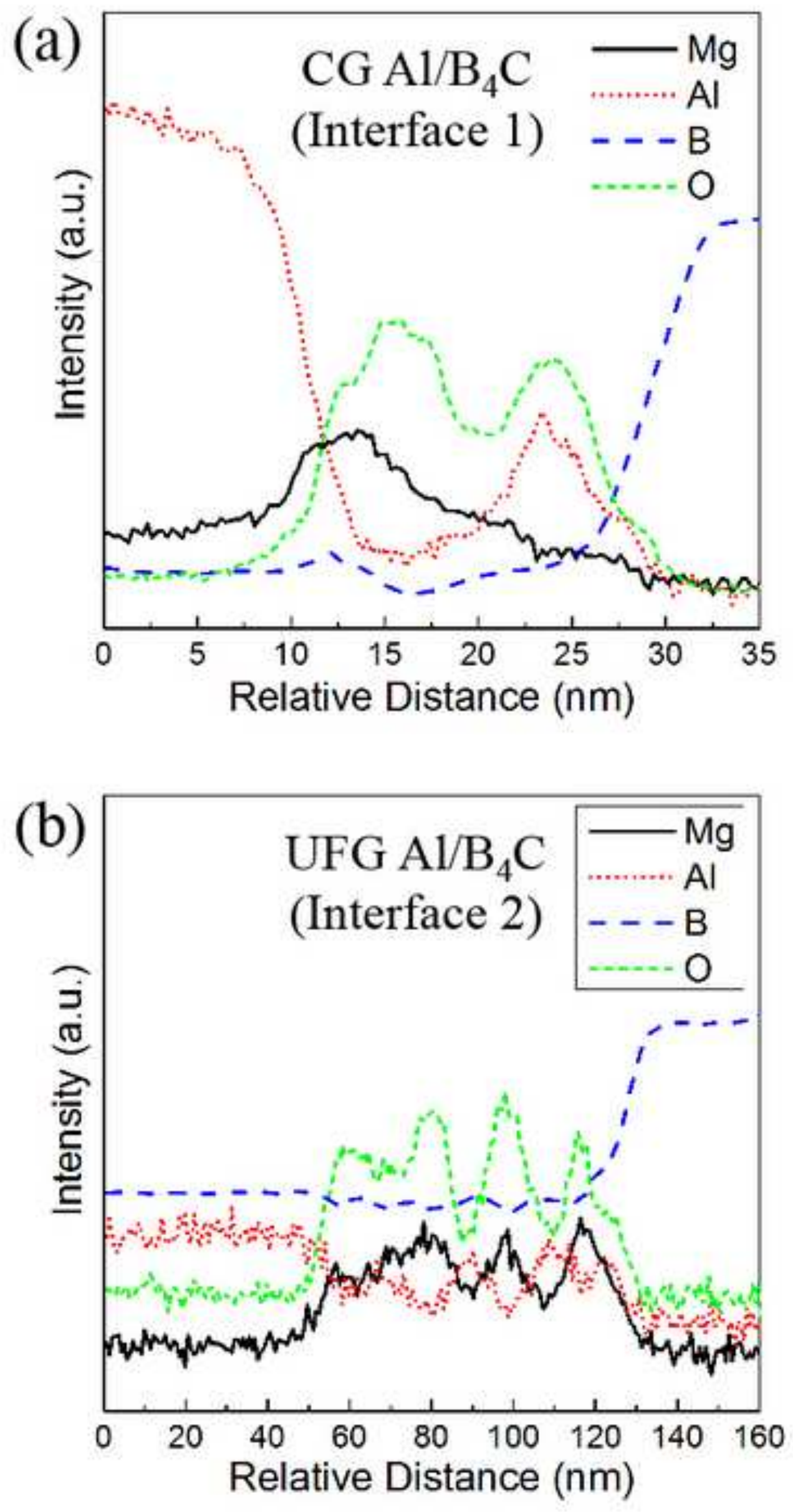

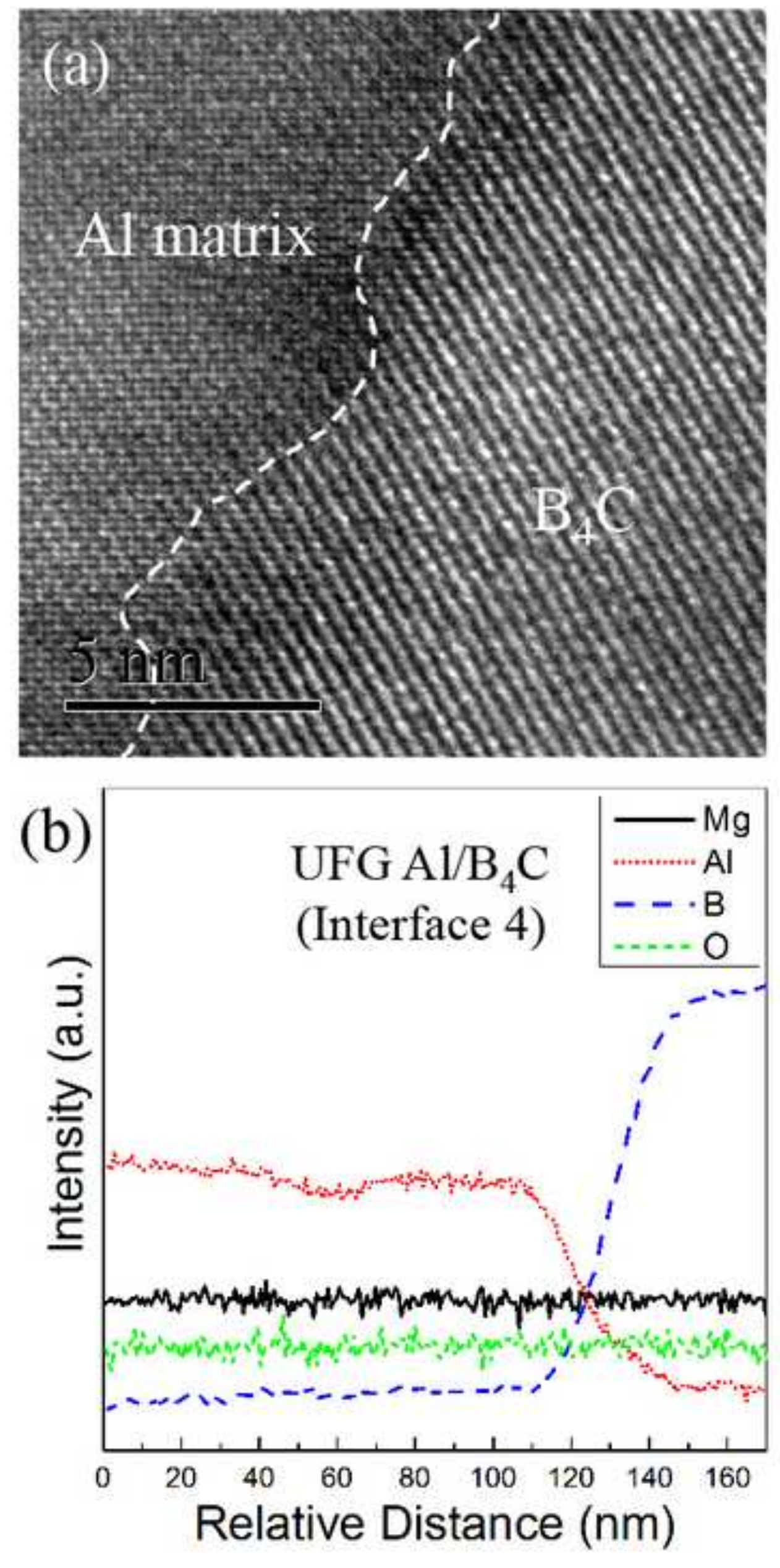

Figure 07

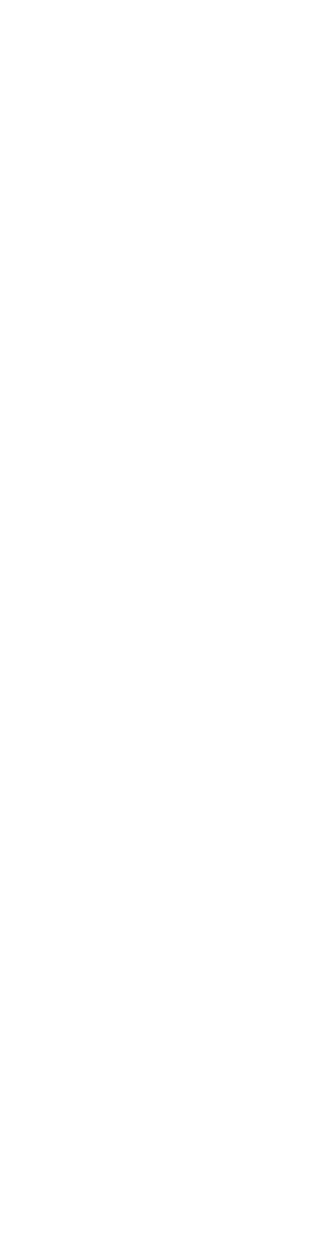

A

Patrix

$$
\text { . }
$$



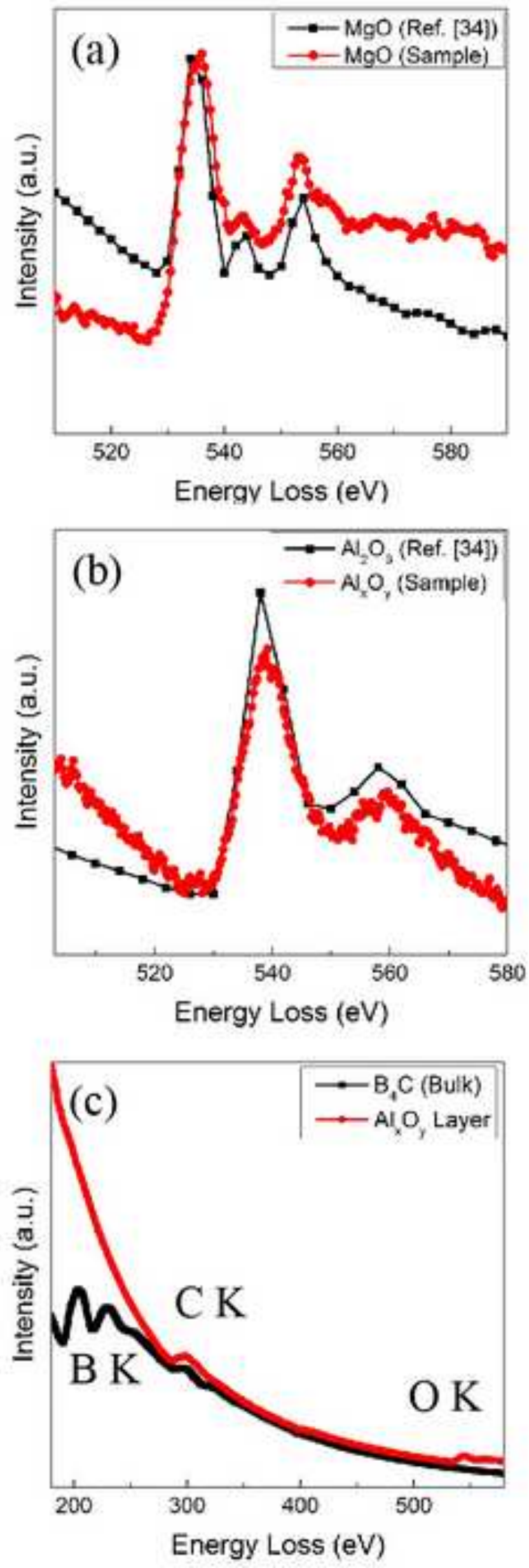

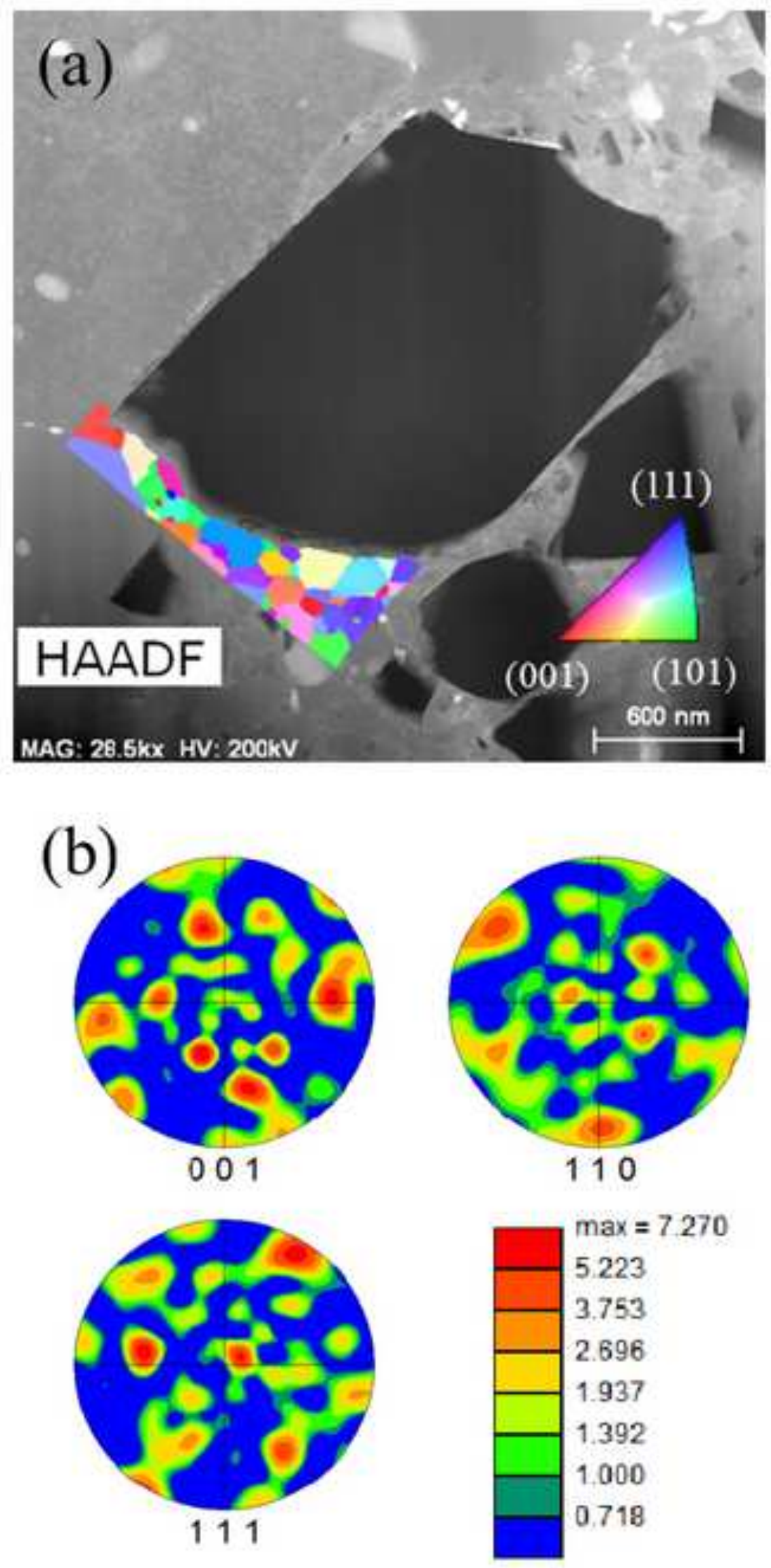

Figure 09

520

5.223

3,753

2.696

1.000

0.718 


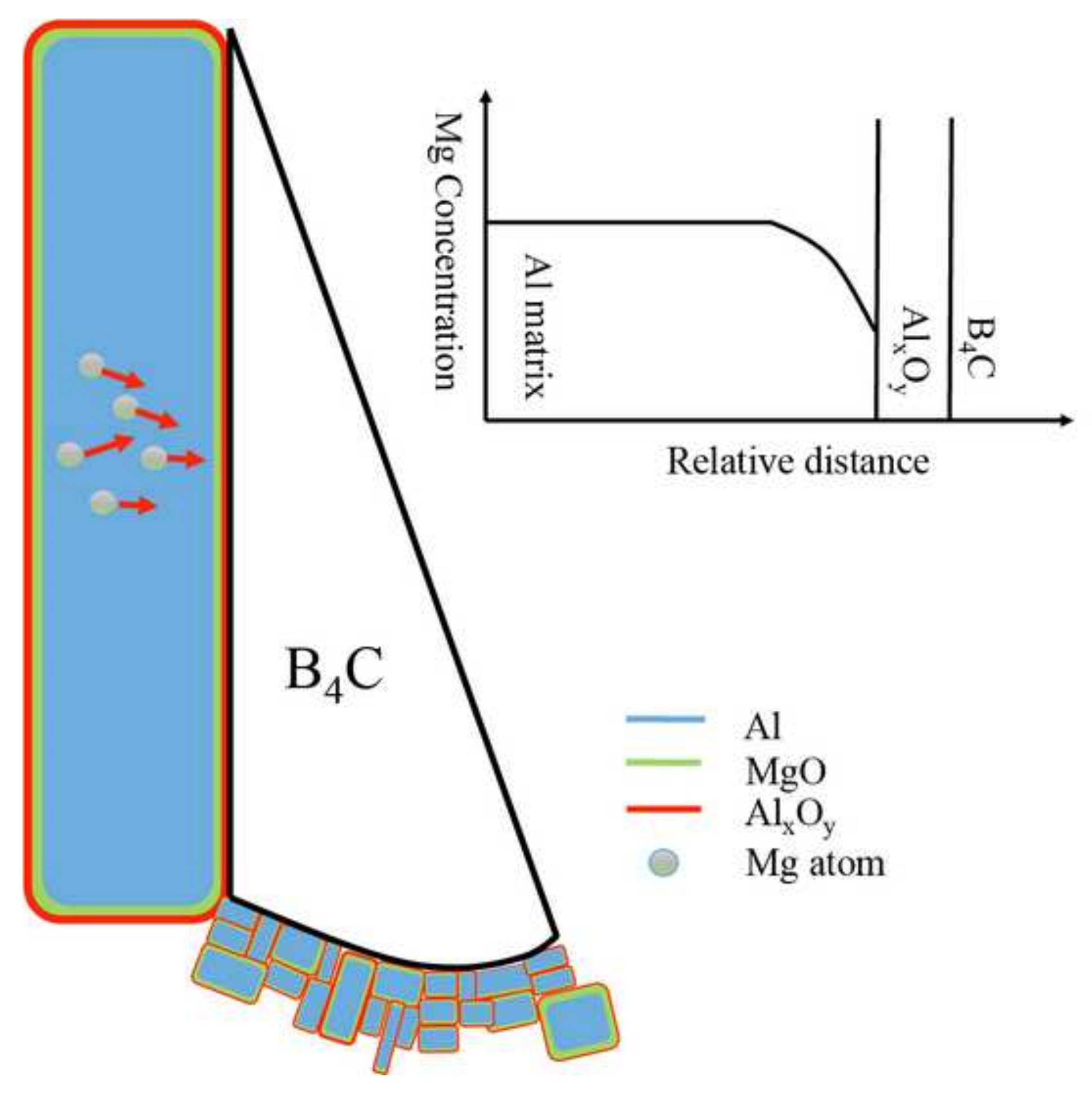


